\title{
Investigation on the performance of bridge approach slab
}

\author{
Amr Abdelrahman ${ }^{1}$, Mohamed Tawfik ${ }^{1}$ and $A$. El-Saify ${ }^{1}$ \\ ${ }^{1}$ Ain Shams University, Cairo, Egypt
}

\begin{abstract}
In Egypt, where highway bridges are to be constructed on soft cohesive soils, the bridge abutments are usually founded on rigid piles, whereas the earth embankments for the bridge approaches are directly founded on the natural soft ground. Consequently, excessive differential settlement frequently occurs between the bridge deck and the bridge approaches resulting in a "bump" at both ends of the bridge deck. Such a bump not only creates a rough and uncomfortable ride but also represents a hazardous condition to traffic. One effective technique to cope with the bump problem is to use a reinforced concrete approach slab to provide a smooth grade transition between the bridge deck and the approach pavement. Investigating the geotechnical and structural performance of approach slabs and revealing the fundamental affecting factors have become mandatory. In this paper, a 2-D finite element model is employed to investigate the performance of approach slabs. Moreover, an extensive parametric study is carried out to appraise the relatively optimum geometries of approach slab, i.e. slab length, thickness, embedded depth and slope, that can yield permissible bumps. Different geo-mechanical conditions of the cohesive foundation soil and the fill material of the bridge embankment are examined.
\end{abstract}

\section{Introduction}

As a result of the current increase in urban development, construction activities have become of essential need in areas of crucial geotechnical conditions, such as construction of highway bridges on soft ground. Whenever a highway bridge has to be constructed on thick layers of soft cohesive subsoil (e.g. soft or very soft clay), the bridge abutments are usually founded on rigid piled foundations. In such a case, the settlement of bridge abutments and, consequently, bridge deck is minimal and frequently considered negligible. The bridge approaches, on the other hand, are commonly constructed of earth embankments that are directly founded on the top of the natural soft ground, and, thus, they are free to settle. The approach embankment settlement is often relatively large 65[1]. Settlement of the approach embankment is attributed mainly to the time-dependent deformations of the soft subsoil.

Consolidation and creep of soft clay, and secondly to the short-term compression of the embankment fill material. In most cases, short-term settlements of the approach embankments are accomplished after construction works have been completed and pavements have been fixed along the bridge. Nevertheless, during the bridge lifetime, consolidation and creep of soft ground below the approach embankments can result in excessive differential settlement between the bridge deck and the adjoining approach pavement. Such a differential settlement emerges as a "bump" at both ends of the bridge deck. The magnitude of the bump is dependent on the bridge specific in-situ conditions. A bridge deck bump not only creates a rough and uncomfortable ride but also represents a hazardous condition to traffic. These defects of the bridge pavements usually require costly maintenance and that often tends to impede the normal flow. Mostly cohesive soil represents a threat instead of cohesion-less soil. Cohesive soil like soft or high plastic clay represents more critical situation.

Cohesive soils are more susceptible to high lateral and vertical movement. Settlements of soil are divided in to three different phases: Initial, primary and secondary consolidation [2]. The initial settlement is a short term settlement when load is applied on the surface of the soil [2].The primary settlement mainly contributes to the total settlement of the soils [3].

The "Bump" can affect drivers varying from feeling uncomfortable to being hazardous to their lives [2]. 
Several solutions have been introduced in practices in order to overcome the bump problem, applying a ground improvement technique such as surcharge (or) preloading, dynamic compaction, compaction piles, grouting, and gravel columns are preferred $[4,5]$ and/or installing approach slabs. The use of approach slabs, however, has been well-recognized as one of the most efficient techniques. To eliminate the effects of the bump, the approach slab must be built to provide a smooth grade transition between these two structures (bridge and roadway). Another function of the approach slab is to keep the magnitude of differential settlement within a control limit $[6,7]$. However, in practice it was found that the approach slabs also exceed differential settlements [6, 7]. Approach slabs are reinforced concrete structural slabs that are often constructed at both ends of the bridge. The slab is supported from one end on the bridge abutment and from the other end on the embankment soil or a sleeper slab [4]. Approach slabs do not prevent the approach embankments from settlement. The fundamental function of approach slabs is to provide a smooth grade transition between the bridge deck and the approach pavement, so that the potential differential settlements can be quite diminished. Nevertheless, their use may result merely in moving a controlled bump from the end of the bridge to the end of the approach slab. Furthermore, feasible settlement of the approach embankment can cause the approach slab to lose its contact and support from the underlying embankment soil. Hence, the slab will bend in a concave manner that may cause a sudden change in the slope grade near its ends and may result in a redistribution of loads to the slab both ends; influencing the slab structural performance. Accordingly, profound understanding of the approach slabs performance, as being transition zones, is essentially required.

A number of comprehensive studies have been presented in the literature over the last few years to discuss and identify the sources of bridges bumps and to introduce specific practical solutions including the approach slabs. However, there is still a need for an extensive investigation on the performance of approach slabs and revealing the fundamental affecting factors. Moreover, clear guidelines for approach slabs design considering the approach embankment settlements have become essentially required. In this regard, the numerical analysis technique will be employed in this research study, through a 2 -D finite element model, to investigate the performance of bridge approach slabs.

\section{Numerical model}

Finite element analysis has been used as one of the numerical techniques for solving problems in the mechanics of continuous media [8]. Nowadays, the finite element plays an important role in all branches of engineering for the analysis and design of the structures [9]. The analysis is typically performed by transforming the physical problem, an actual structure and structural components, into a mathematical model [9].
The purpose of the numerical analysis is to evaluate the behavior of the approach slabs and give recommendations to design the approach slab according to the international standards. This paper used "PLAXIS" to simulate the behavior of the transition zone, including the bridge abutment, the piles, the approach slab, the embankment and the subsoil material.

\subsection{Model configuration}

One of the most important steps in numerical simulations is to determine where the boundaries should be placed. In this paper, it is assumed that the boundary is located $35 \mathrm{~m}$ below the bottom of the fill embankment and the horizontal distance from the approach slab to the end of the embankment is $30 \mathrm{~m}$. A schematic of the model is shown in Figure (1). Figure (2) shows a finite element model to simulate the bump at the free end of the approach slab.

Using the finite element model described above, this paper simulated several cases. The thickness, the length, the embedded depth and varying thickness of the approach slab were changed to study their influence on the bump at the free end of the approach slab. The different properties of materials which used in this study are shown in Tables (1) and (2).

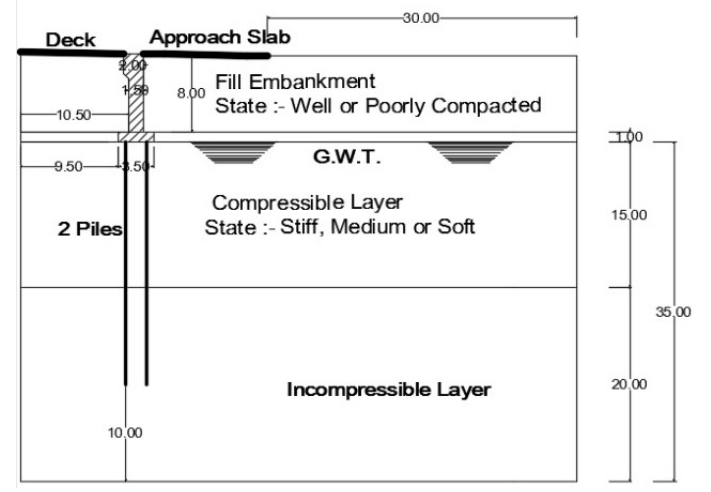

Fig. 1. General configuration and parameters the used in analytical model

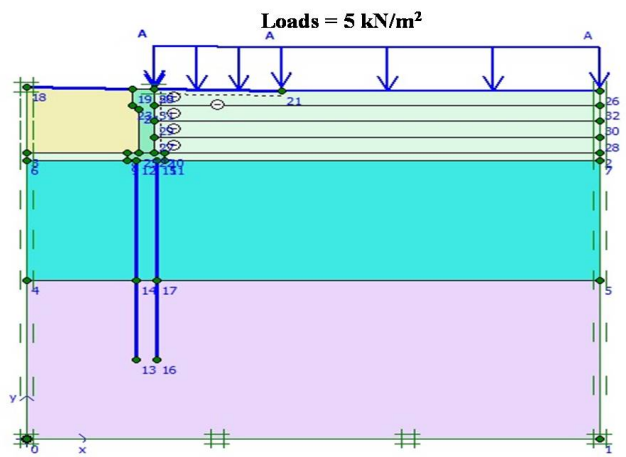

Fig. 2. Loads and discretization of the utilized analytical model 
Table 1. Properties of plates used in the model

\begin{tabular}{|c|c|c|c|}
\hline $\begin{array}{c}\text { EA } \\
(\mathrm{kN} / \mathrm{m})\end{array}$ & Approach Slab & Deck & Piles \\
\hline $\begin{array}{c}\text { EI } \\
\left(\mathrm{kN} \cdot \mathrm{m}^{2} / \mathrm{m}\right)\end{array}$ & Variable & $\begin{array}{c}2.5 \mathrm{X} \\
10^{6}\end{array}$ & $6.032 \times 10^{7}$ \\
\hline $\mathrm{d}(\mathrm{m})$ & 1 & 1 & Pile D=0.8 \\
\hline $\begin{array}{c}\mathrm{w} \\
(\mathrm{kN} / \mathrm{m} / \mathrm{m})\end{array}$ & 7.5 & 25 & 15 \\
\hline$v$ & 0.2 & 0.2 & 0.2 \\
\hline
\end{tabular}

Notations: Where ${ }^{{ } \text {Unsat }}$ : Bulk unit weight, ${ }^{{ }}{ }_{\text {Sat }}$ : Saturation unit weight, $\mathrm{E}_{\text {ref }}$ : Young's modulus, C: Cohesion, $\Phi$ : Friction angle, $\Psi$ : Dilatancy angle, v: Poission's ratio, $\mathrm{R}_{\text {inter: }}$ : Strength reduction factor inter, EA: Normal stiffness, EI: Flexural rigidity, d: Equivalent thickness, w: weight.
The description of the utilized numerical model is presented and properties of soils and plates are carefully defined. A Figure (3) shows the configuration of the basic analytical model used to investigate the performance of the approach slab.

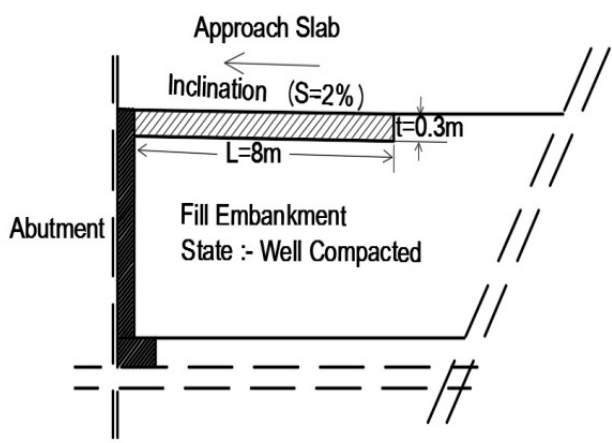

Fig. 3. Basic Model

Table 2. Properties of concrete, incompressible layer, compressible layer and fill embankment used in the model

\begin{tabular}{|c|c|c|c|c|c|c|c|}
\hline & & & \multicolumn{3}{|c|}{ Compressible Layer } & \multicolumn{2}{|c|}{ Fill Embankment } \\
\hline & Concrete & $\begin{array}{l}\text { Incompressible } \\
\text { Layer }\end{array}$ & $\begin{array}{l}\text { Soft } \\
\text { Clay }\end{array}$ & $\begin{array}{l}\text { Medium } \\
\text { Clay }\end{array}$ & $\begin{array}{l}\text { Stiff } \\
\text { Clay }\end{array}$ & $\begin{array}{c}\text { Well } \\
\text { Compacted Fill }\end{array}$ & $\begin{array}{c}\text { Poorly } \\
\text { Compacted Fill }\end{array}$ \\
\hline $\begin{array}{c}\text { Material } \\
\text { Model }\end{array}$ & $\begin{array}{l}\text { Linear } \\
\text { Elastic }\end{array}$ & $\begin{array}{l}\text { Mohr- } \\
\text { Coulomb }\end{array}$ & $\begin{array}{c}\text { Mohr- } \\
\text { Coulomb }\end{array}$ & $\begin{array}{c}\text { Mohr- } \\
\text { Coulomb }\end{array}$ & $\begin{array}{c}\text { Mohr- } \\
\text { Coulomb }\end{array}$ & Hardening Soil & Hardening Soil \\
\hline $\begin{array}{c}\text { Material } \\
\text { Type }\end{array}$ & $\begin{array}{c}\text { Non- } \\
\text { porous }\end{array}$ & Drained & Drained & Drained & Drained & Drained & Drained \\
\hline $\begin{array}{c}{ }^{\mathrm{y}} \text { Unsat } \\
\left(\mathrm{kN} / \mathrm{m}^{3}\right)\end{array}$ & 25 & 22 & 16 & 17 & 17.5 & 20 & 18 \\
\hline $\begin{array}{c}{ }_{\mathrm{S}}^{\mathrm{V} a t} \\
\left(\mathrm{kN} / \mathrm{m}^{3}\right)\end{array}$ & & 22 & 16 & 17 & 17.5 & 20 & 18 \\
\hline $\begin{array}{c}\mathrm{E}_{\mathrm{ref}} \\
\left(\mathrm{kN} / \mathrm{m}^{2}\right)\end{array}$ & $3 \times 10^{7}$ & $1 \times 10^{7}$ & 1500 & 3000 & 6000 & $1 \times 10^{4}$ & $7 \times 10^{3}$ \\
\hline $\begin{array}{c}\mathrm{C} \\
\left(\mathrm{kN} / \mathrm{m}^{2}\right)\end{array}$ & & 3000 & 15 & 30 & 45 & 0.1 & 0.1 \\
\hline$\Phi$ (Degree) & & 30 & 10 & 20 & 25 & 35 & 32 \\
\hline$\Psi$ (Degree) & & 0 & 0 & 0 & 0 & 0 & 0 \\
\hline $\mathrm{v}$ & 0.25 & 0.25 & 0.35 & 0.3 & 0.28 & & \\
\hline Power & & & & & & 0.5 & 0.5 \\
\hline $\mathrm{R}_{\text {inter }}$ & & & & & & 0.67 & 0.67 \\
\hline
\end{tabular}




\subsection{Behavior of the model}

A typical two-dimensional model is shown in Figure (4) using "PLAXIS" software, which contains facilities for automatic mesh generation. The figure illustrates a typical mesh, which is used in the numerical model representing the soil and approach slab.

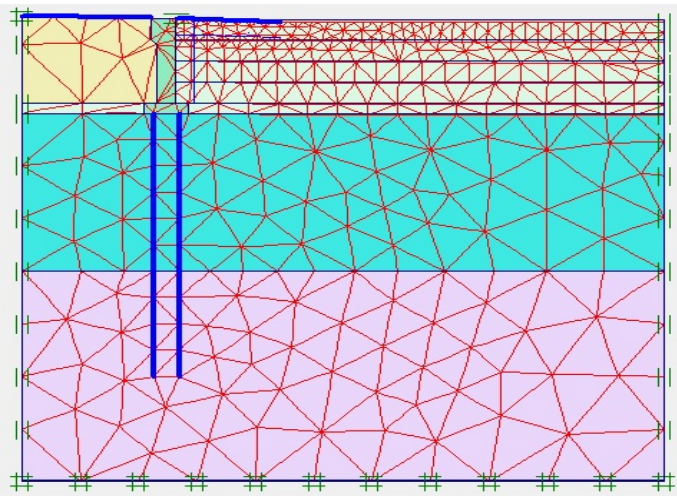

Fig. 4. The deformed mesh of the utilized model

The analysis results of the numerical model are represented in Figures (5) through (7), due to actions of the applied loads. Figure (5) shows the total displacements occurring in the embankment and the approach slab. Figures (6) and (7) show the vertical soil displacements and the horizontal soil movements, respectively. The pattern of color shades from the results of the vertical movements is quite similar to the pattern of the results of total movements shown in Figure (5), which indicates that the vertical movement is the predominant factor in this study.

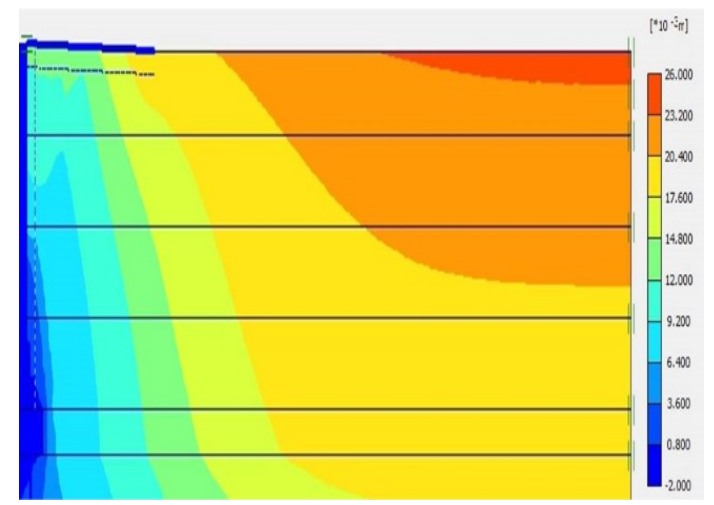

Fig. 5. Total displacement of the basic model

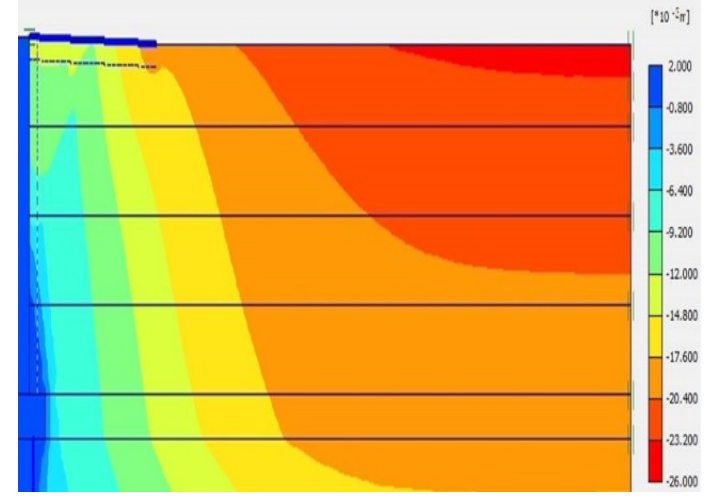

Fig. 6. Vertical displacement of the basic model

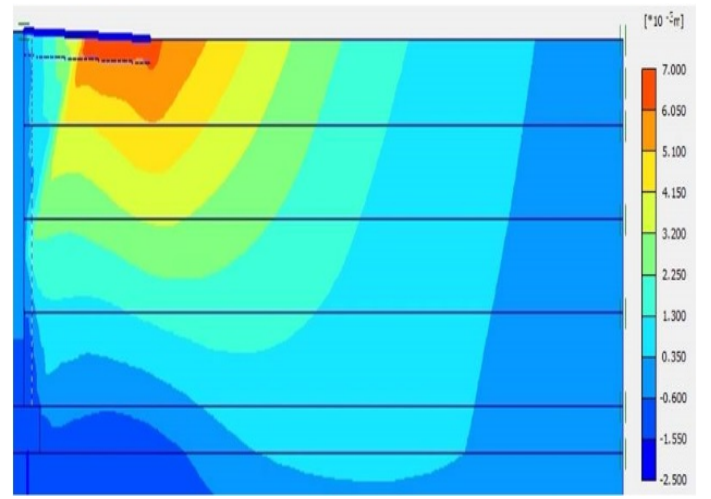

Fig. 7. Horizontal displacement of the basic model

\subsection{Behavior of the approach slab}

When the approach slab is loaded with the applied loads, straining actions for the slab represented in bending moment are shown in Figure (8). The effective normal stress on soil below the approach slab is shown in Figure (9).

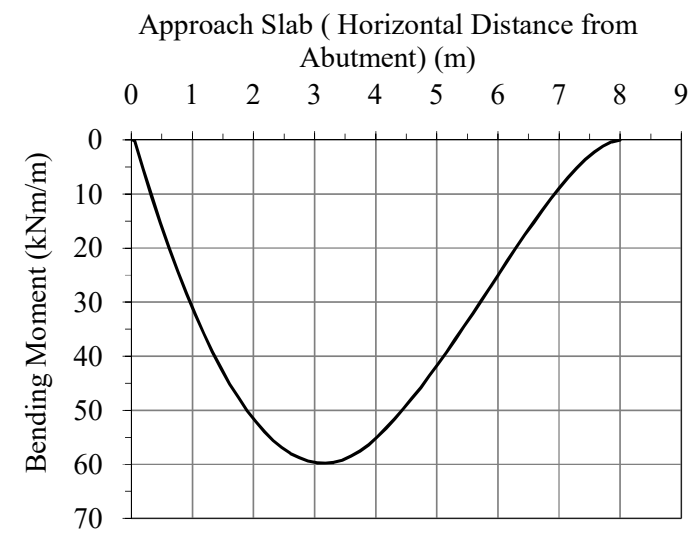

Fig. 8. Bending moment of the approach slab 


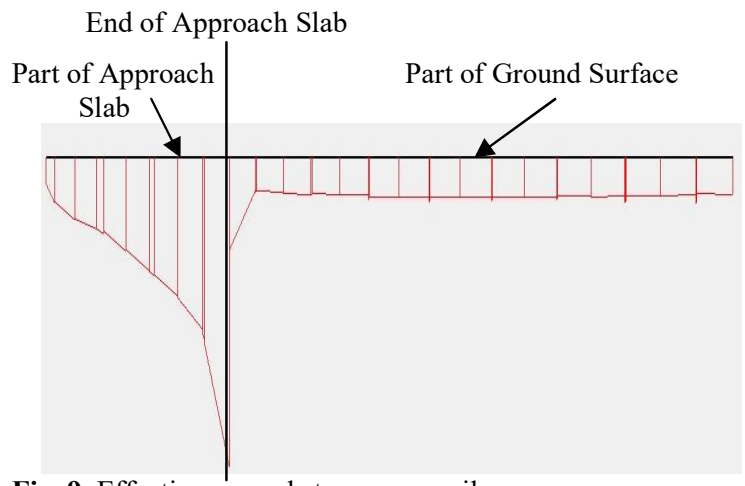

Fig. 9. Effective normal stresses on soil

\subsection{Formation of the bump}

Figures (10) and (11) show the settlement of the approach slab and soil. It is evident that a bump is formed at the free end of the approach slab because of the different stiffness between the approach slab and the soil as shown in Figure (9). Total settlement at the free end of the approach slab $\left(\Delta_{0}\right)$ and relative bump value defined as the differential settlement in $3 \mathrm{~m}$ width at the free end of the approach slab $\left(\Delta_{b}\right)$, are shown in these Figures.

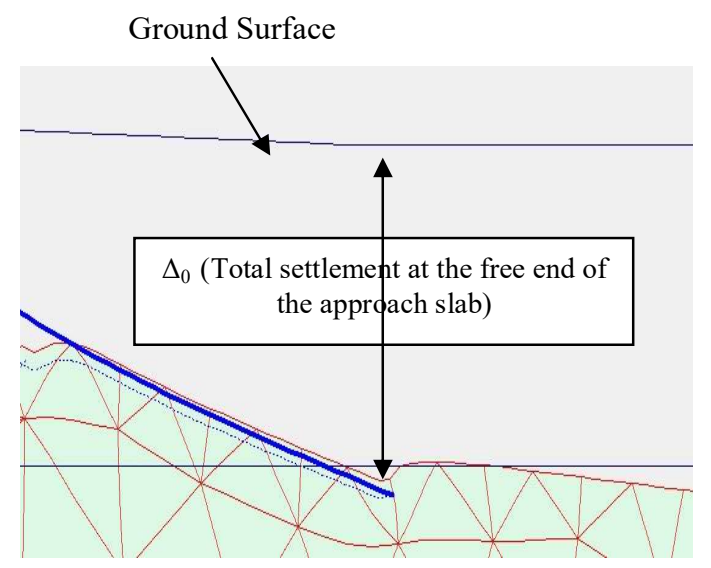

Fig. 10. The deformed mesh of the utilized model

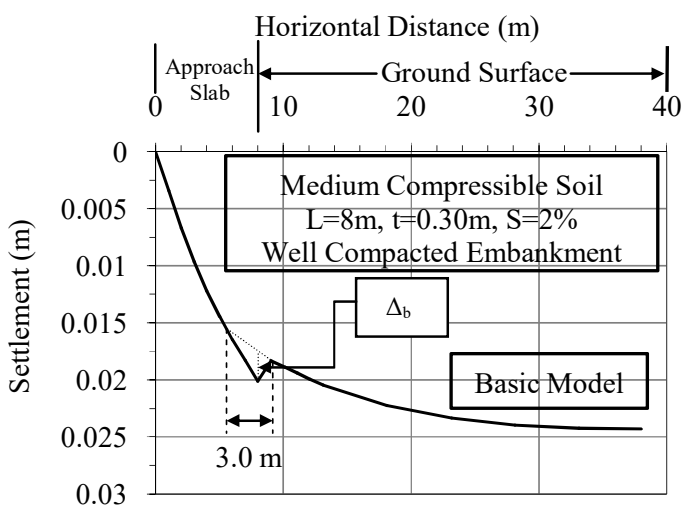

Fig. 11. Total settlement and relative bump at the free end of the approach slab

\section{Effect of the approach slab length}

A parametric study was performed to investigate the effect of different factors on the behavior of the approach slab and to examine the mechanism of bump at the end of the approach slab. The examined parameters included different fill embankment and different types of compressible soil. Different lengths (L) of approach slabs starting from 8 up to $20 \mathrm{~m}$ were studied. The thickness of the slab was $0.30 \mathrm{~m}$ and the slope was $2 \%$. These analyses were studied with different types of compressible soil, soft, medium or stiff, and different types of fill embankment, well or poorly compacted.

\subsection{Effect of compressible soil}

By analyzing the results from the finite element models using different compressible soil and well compacted embankment, Figure (12) illustrates that an increase in the approach slab length leads to an increase in the total settlement at the free end of the approach slab. In case of soft compressible soil, the total settlement at the free end is higher than that for the medium or stiff soil. The total settlement at the free end of the approach slab is constant regardless of the slab length in case of having medium or stiff soil; however, the settlement is increasing in case of having soft soil with the increase of the slab length.

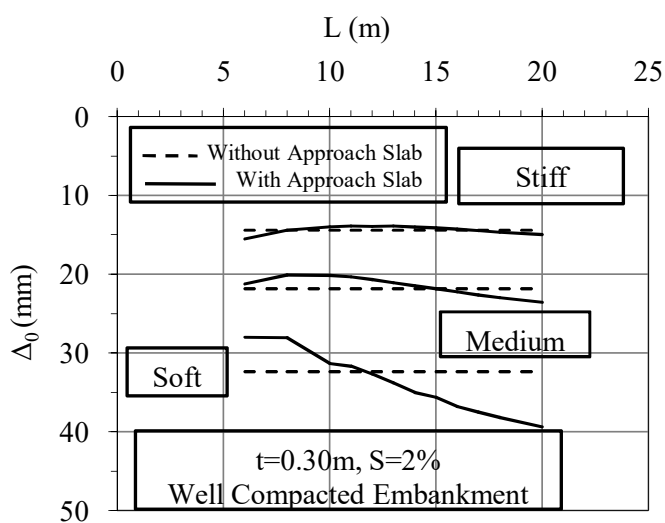

Fig. 12. Effect of length of the approach slab (L) on total settlement at the free end of the approach slab $\left(\Delta_{0}\right)$

Figure (13) illustrates that the relative value of the bump at the free end of the approach slab is inversely proportional to the length of the approach slab. For different compressible soils, increasing the length of the approach slab leads to a decrease in the relative bump value within $3 \mathrm{~m}$ width at its the free end. When the approach slab length increases more than $13 \mathrm{~m}$, there is almost no change in the relative bump value within a $3 \mathrm{~m}$ width at the free end of the approach slab. 


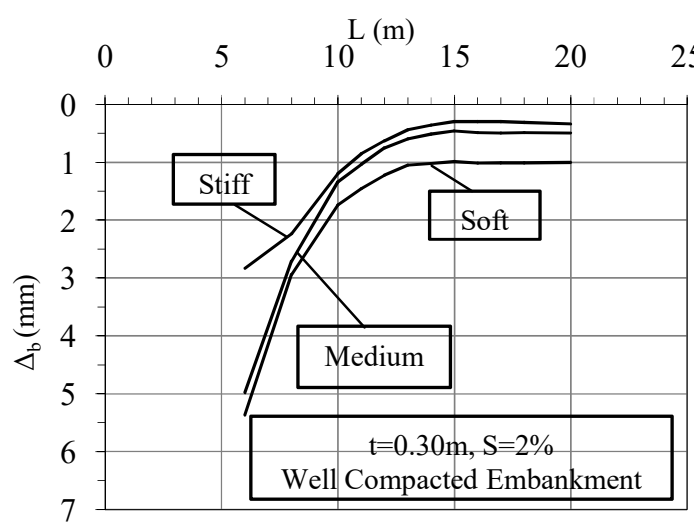

Fig. 13. Effect of different compressible soils on the relative bump value at the free end of the approach slab

Figure (14) shows the change in the maximum bending moment in the approach slab for compressible soils. The maximum bending moment on the slab $\left(\mathrm{M}_{\max }\right)$ increases with the increase of the slab length. The maximum moment also increases for soft soil compared to medium or stiff soils for the same length. The figure also shows that there is no change in the maximum slab bending moment when the slab length is more than 12 , 14 and $16 \mathrm{~m}$ for the soft, medium and stiff soil, representatively.

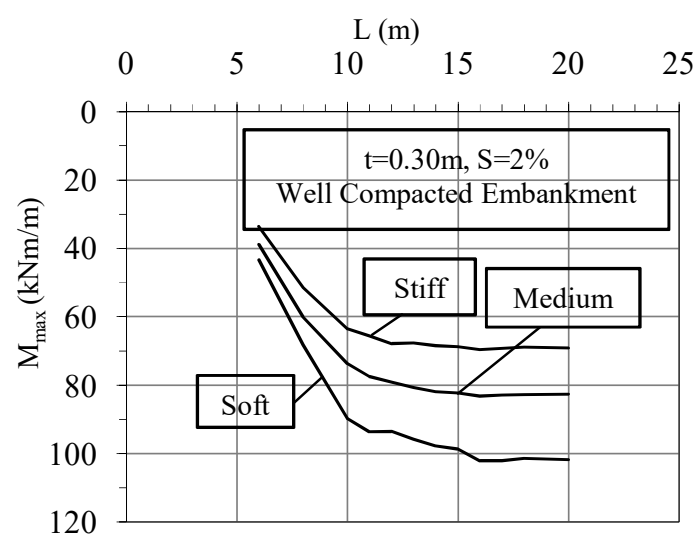

Fig. 14. Maximum bending moment of the approach slab $\left(\mathrm{M}_{\max }\right)$

Figure (15) shows the normal stress at the free end of the approach slab. The figure shows that the normal stresses decrease with increase of the slab length. When the approach slab length (L) increases more than $15 \mathrm{~m}$ for different cases of compressible soils (stiff, medium, soft), there is almost no change in the normal stresses at the free end of the slab $\left(\sigma_{\mathrm{N}}\right)$.

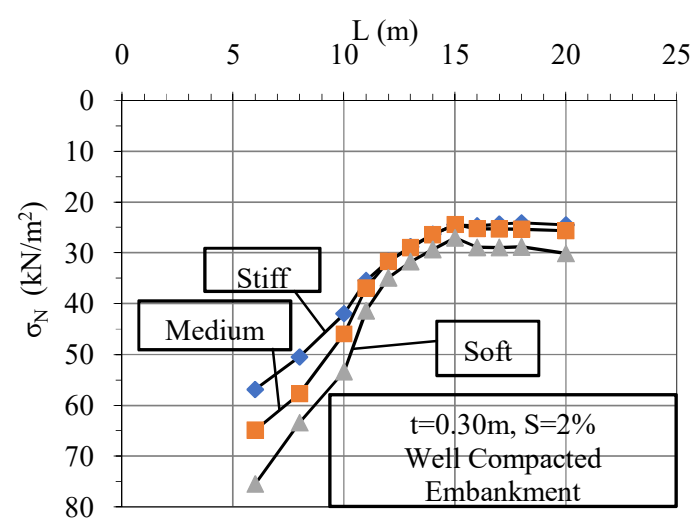

Fig. 15. Normal stresses at the free end of the approach slab $\left(\sigma_{\mathrm{N}}\right)$

\subsection{Effect of embankment compaction}

Analysis was carried out for different compacted fill embankment and medium compressible soil. Figure (16) shows that the relative bump value within $3 \mathrm{~m}$ width at the free end of the approach slab $\left(\Delta_{b}\right)$ increases for poorly compacted fill compared to the well compacted fill. When the length of the approach slab (L) increases more than (13 and 16) $\mathrm{m}$ for the well and poorly compacted embankment, there is almost no change in the relative bump value.

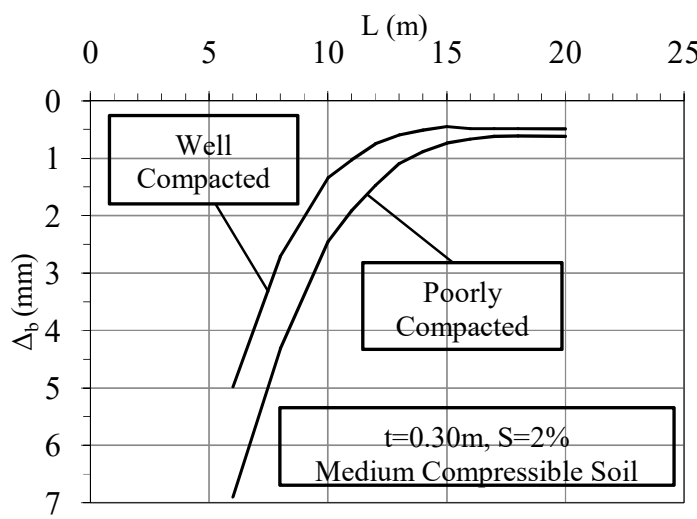

Fig. 16. Effect of fill embankment on the relative bump

\section{Thickness of the approach slab}

The parametric study was extended to investigate the effect of slab thickness on the general behavior of the approach slab. In this 2-D analysis, $12 \mathrm{~m}$ length approach slab was studied. The thickness was $0.15,0.20,0.25$, $0.28,0.30,0.32,0.35,0.40$ or $0.50 \mathrm{~m}$ with a slope of $2 \%$. These slab analyses were studied with medium compressible soil and different cases of fill embankment, well or poorly compacted.

By analyzing the results from the finite element, the thickness of the approach slab and the value of the bump at the free end of the approach slab are directly proportional. This means that increasing the thickness of the approach slab leads to an increase in the total settlement at the free end of the approach slab $\left(\Delta_{0}\right)$. 
Figure (17) illustrates that an increase in the thickness of the approach slab leads to an increase in the relative bump value within a $3 \mathrm{~m}$ width at the free end of the approach slab $\left(\Delta_{b}\right)$ because the increase in the weight of the approach slab and the relative stiffness between the slab and soil.

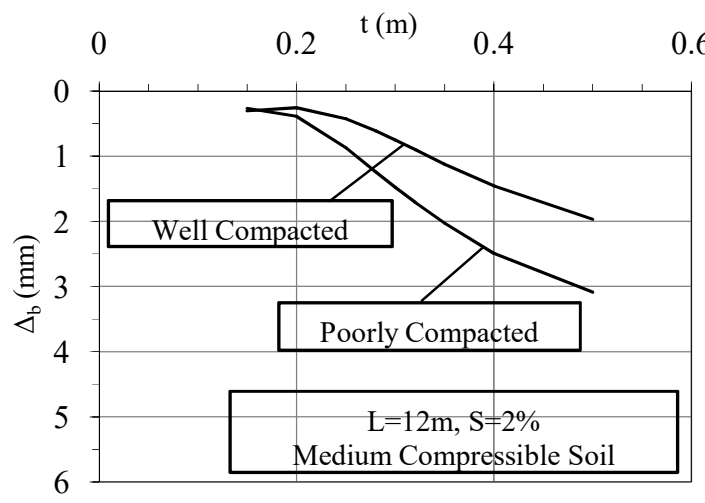

Fig. 17. Effect of thickness of the approach slab (t) on the relative bump

\section{Effect of embedded depth at the free end of the approach slab}

A parametric study was performed to investigate the effect of embedding the slab below the ground level. In this 2-D finite element analysis, 1, 1.5, 2, or $2.5 \mathrm{~m}$ embedded depth at the free end of the approach slab (Z) was studied, as shown in Figure (18). The slab length was $12 \mathrm{~m}$ with thickness of $0.30 \mathrm{~m}$. These analyses were studied with different cases of compressible soil, soft, medium or stiff, and well compacted fill embankment.

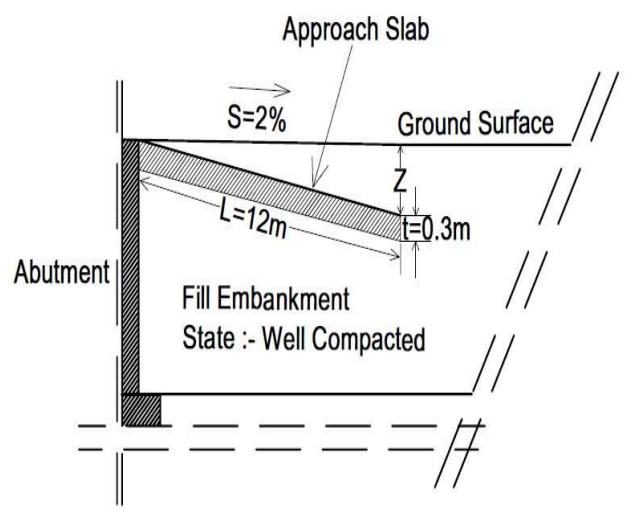

Fig. 18. General configuration

By analyzing the results from the finite element analyses, it was found out that the embedded depth at the free end of the approach slab $(Z)$ and the value of the bump at the free end of the approach slab are inversely proportional. This means that an increase the embedded depth leads to a decrease in the relative bump value within $3 \mathrm{~m}$ width at the free end of the approach slab $\left(\Delta_{\mathrm{b}}\right)$, as shown in Figure (19).

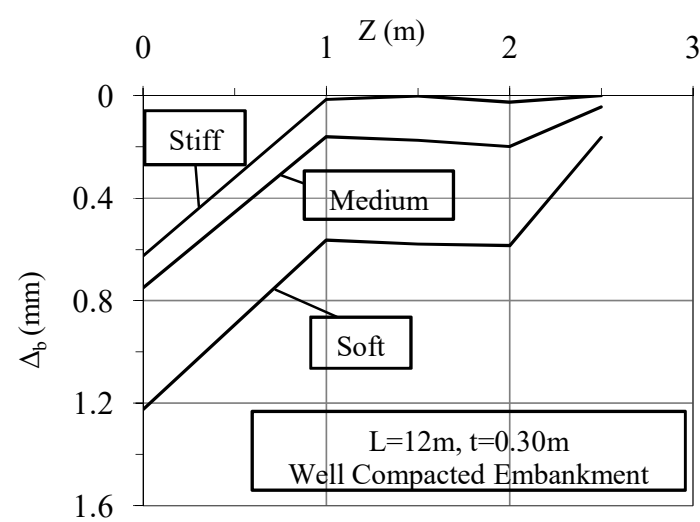

Fig. 19. Effect of embedded depth at the free end of approach slab $(Z)$ on relative bump value within $3 \mathrm{~m}$ width at the free end of the approach slab $\left(\Delta_{\mathrm{b}}\right)$.

Figure (20) illustrates that an increase in the embedded depth at the free end of the approach slab $(Z)$ leads to an increase in the maximum bending moment on the approach slab $\left(\mathrm{M}_{\max }\right)$ because of increasing the applied loads on the approach slab.

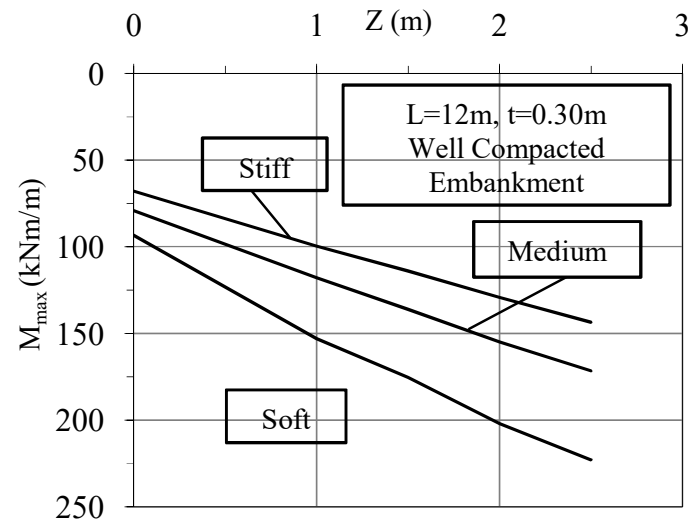

Fig. 20. Maximum bending moment on the approach slab $\left(\mathrm{M}_{\max }\right)$

\section{Effect of variable thickness of approach slab}

The parametric study was performed to investigate the relative effect of different factors on the behavior of performance of the approach slab to examine the mechanism of bump between the approach slab and fill embankment that represent different cases of compressible soil. In this 2-D finite element analysis, the length was $12 \mathrm{~m}$ and the thickness of it was a variance $\left(t_{1}\right.$ : Thickness of approach slab in the direction of abutment, $t_{2}$ : Thickness at the free end of approach slab), as shown in Figure (21). This analysis was studied with different cases of compressible soil, soft, medium or stiff, and fill embankment was well compacted. 


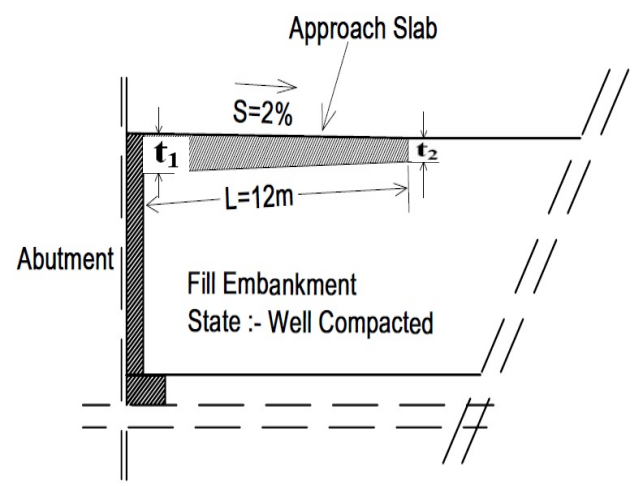

Fig. 21. General configuration.

By analyzing the results from the finite element analysis, which the varying thickness of the approach slab has almost no effect on the total settlement at the free end of the approach slab $\left(\Delta_{0}\right)$. However, decreasing the varied thickness of the approach slab leads to an increase in the effect normal stresses at the free end of the approach slab $\left(\sigma_{\mathrm{N}}\right)$. It is clear from Figure (22), that the varying thickness of approach slab has almost no effect on the relative bump value within a $3 \mathrm{~m}$ width at the free end of the approach slab $\left(\Delta_{\mathrm{b}}\right)$.

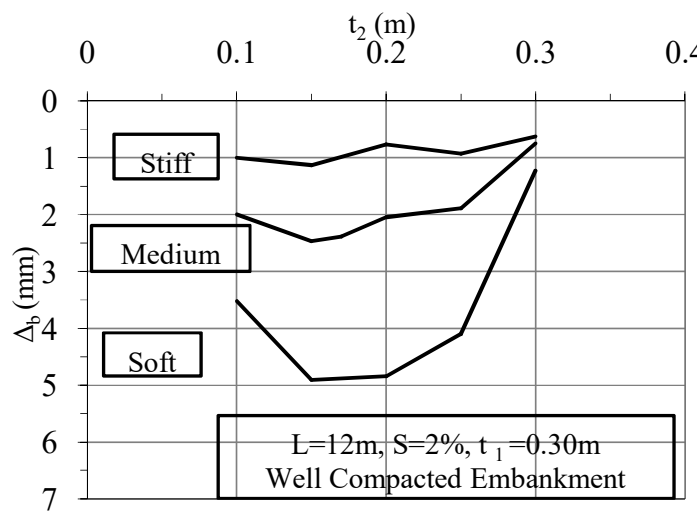

Fig. 22. Effect of variable thickness at the free end of the approach slab $\left(\mathrm{t}_{2}\right)$ on relative bump value within $3 \mathrm{~m}$ width at the free end of the approach slab $\left(\Delta_{b}\right)$.

\section{Conclusions}

An appropriate approach slab design directly affects the safety and economy of the transportation infrastructure. A rational design is necessary not only for the serviceability requirement of the transition approach slab, but also for the life expectancy of the whole highway system including bridges and pavements. As the bump problem has existed for years, the design of the approach slab is still more an art than a science. Engineering calculations of the approach slab are typically not conducted or the approach slab is simply designed as a simply-supported beam since the information about the interaction of the approach slab and the embankment settlement is unknown for a routine office design. There are no AASHTO guidelines for designing approach slabs considering a given embankment settlement.
The present study investigated the effect of different factors on the behavior of approach slab that represent different cases of compressible soil and embankment soil. The investigated factors were as follows: the length of approach slab; the thickness of approach slab; the embedded depth at the free end of approach slab and the varying thickness of approach slab. Total settlement at the free end of the approach slab $\left(\Delta_{0}\right)$, the relative bump value within a $3 \mathrm{~m}$ width at the free end of the approach slab $\left(\Delta_{b}\right)$, the normal stresses at the free end of the approach slab $\left(\sigma_{N}\right)$ and the maximum bending moment on approach slab $\left(\mathrm{M}_{\max }\right)$ were predicted with finite element modeling. The best approach slab recommended in this paper is from $12 \mathrm{~m}$ to $14 \mathrm{~m}$ length, $0.3 \mathrm{~m}$ thickness and the embedded depth with more than $1 \mathrm{~m}$.

It is concluded from this study that the most effective design of the approach slab in order to reduce the pumps at the end of the slab can be achieved by the following

1. Total length of the approach slab is more than $12 \mathrm{~m}$.

2. Thickness of the approach slab is more than or equal $0.30 \mathrm{~m}$.

3. Inclining the approach slab away from the bridge deck to achieve a depth not less than $1.0 \mathrm{~m}$ below ground surface at the end of the slab.

\section{References}

1. J.L.Briaud, R.W. James, S.B.Hoffman, NCHRP synthesis 234: Settlement of Bridge Approaches (the bump at the end of the bridge), Transportation Research Board, National Research Council, D.C.Washington, pp.75(1997).

2. T.C.Hopkins, "Settlement of Highway Bridge Approaches and Embankment Foundations." Rep. No. KYHPR-64-17; HPR-1(4), Kentucky Transportation Center, Lexington, Kentucky(1969).

3. T.C.Hopkins, "Settlement of Highway Bridge Approaches and Embankment Foundations" Rep. No. KYHPR-64-17; HPR-1(8), Kentucky Transportation Center, Lexington, Kentucky, 40(1973).

4. H.E.Wahls, "Design and Construction of Bridge Approaches"NCHRP Synthesis of Highway Practice No. 159, Transportation Research Board, National Research Council, D.C. Washington (1990).

5. N.Abu-Hejleh, D. Hanneman, D.J. White, I.Ksouri, "Flowfill and MSE Bridge Approaches: Performance, Cost and Recommendations for Improvements" Report No. CDOT-DTD-R-2006-2, ColoradoDepartmentof Transportation, Denver(2006).

6. J.G. Laguros,M.M.Zaman, I.U.Mahmood, "Evaluation of Causes of Excessive Settlements of Pavements Behind Bridge Abutments and their Remedies; Phase II. (Executive Summary)" Rep. No. FHWA/OK 89 (07), Oklahoma Department of Transportation(1990). 
7. E.J.Hoppe, "Guidelines for the Use, Design, and Construction of Bridge Approach Slabs" Rep. No. VTRC 00-R4, Virginia Transportation Research Council, VA.Charlottesville, (1999).

8. A.K.Bugrov, "The Finite Element Method in Consolidation Analyses of Water- Saturated Soils" Power Technology and Engineering (Formerly Hydrotechnical Construction), 9, 7, 661-668(1975).

9. K.J. Bathe,Finite Element Procedures, Prentice-Hall of India, New Delhi(2003).

10. J.Horvath,"Integral Abutment Bridges: Problem and Innovative Solutions Using EPS Geofoam and other Geosynthetics" Research Report No. CE/GE-00-2, Manhattan College, Bronx, New York(2000).

11. J. Kunin, S.Alampalli, "Integral Abutment Bridges: Current Practice in United States and Canada" ASCE Journal of Performance of Constructed Facilities, 14(3), 104-111(2000).

12. J.Seo, "The Bump at the End of the Bridge: An Investigation" Dissertation submitted in partial fulfillment of the requirements for the degree of the Doctor of Philosophy, Texas, A\&M University, College Station, Texas(2003). 